\title{
Preliminary screening of polybrominated diphenyl ethers (PBDEs), hexabromocyclododecane (HBCDD) and tetrabromobisphenol A (TBBPA) flame retardants in landfill leachate
}

\author{
Adegbenro P. Daso ${ }^{1,2,}$, Egmont R. Rohwer ${ }^{1}$, Dwayne J. Koot ${ }^{1}$, Jonathan O. Okonkwo² \\ ${ }^{1}$ Department of Chemistry, Faculty of Natural and Agricultural Sciences, University of Pretoria, Private Bag \\ X20, Hatfield 0028, Pretoria, South Africa. \\ ${ }^{2}$ Department of Environmental, Water and Earth Sciences, Tshwane University of Technology, 175 Nelson \\ Mandela Drive, Private Bag X680, Arcadia, Pretoria, South Africa. \\ *Corresponding author: Tel: +27789027213, +27746546510; Fax: +27124204687; \\ adegbenrop@gmail.com; adegbenroPD@tut.ac.za
}

\begin{abstract}
The occurrence of selected brominated flame retardants, including nine PBDE congeners, HBCDD and TBBPA in leachate samples from 8 landfill sites in South Africa were investigated. In addition, the possible influences of dissolved organic carbon on their levels were also evaluated. Filtered leachate samples were subjected to solid-phase extraction to isolate the various target compounds. PBDEs with six bromine substituents and above, as well as $\alpha-H B C D D, \beta-H B C D D$ and TBBPA were generally found below the detection limit. However, the mean value of the total lower PBDE congeners ranged between 0.04 and $0.48 \mu \mathrm{g} \mathrm{L}^{-1}$ and the concentrations of $\mathrm{\gamma}$-HBCDD ranged from not detectable (ND) to $0.05 \mu \mathrm{g} \mathrm{L} \mathrm{L}^{-1}$. No significant correlation was observed between the target compounds and DOC, although weak to moderate correlations were mostly observed for the lower PBDEs.
\end{abstract}

Keywords: PBDEs, hexabromocyclododecane, tetrabromobisphenol A, landfill leachate, South Africa.

\section{Introduction}

Brominated flame retardants (BFRs) are classified as industrial chemicals with high production volume and are mainly employed for fire retardation purposes (WHO/IPCS 1994, 1997). Among these groups of chemicals, polybrominated diphenyl ethers (PBDEs), hexabromocyclododecane (HBCDD) and 
tetrabromobisphenol A (TBBPA) have been critically evaluated due to their ubiquitous distribution in the environment (Chokwe et al. 2015, Muenhor et al. 2010, Zeng et al. 2014). As a result of their excellent flame retardant properties, some of these chemicals are still widely used in different industrial applications (Gorga et al. 2013). PBDEs, which are commonly produced in three different commercial formulations (penta-, octa- and deca-BDE), are mostly used as additives in polymers used in plastic casing of electronics, computers, textiles and furniture (de Wit 2002). The technical HBCDD, on the other hand, consists of three diastereoisomers (namely: $\alpha, \beta$ and $\gamma$ ), and it is primarily used to flame retard extruded and expanded polystyrene commonly used for thermal insulation in buildings, and sometimes in upholstery textiles (Morris et al. 2004). In contrast, TBBPA is covalently bound to the polymeric material during the manufacturing process. Its primary area of application is in the electronic circuit boards of electrical and electronic appliances.

Due to concerns over their environmental persistence, toxicity, bioaccumulation potential and their propensity to undergo long-range atmospheric transport, the production and use of the penta-, octaBDEs as well as HBCDD technical formulations have been globally restricted (UNEP 2009). Presently, only TBBPA and deca-BDE technical formulations are still being produced, although there are concerns over the possible microbial mediated or photolytic breakdown of the deca-BDE congener to the more toxic lower brominated congeners (Daso et al. 2010). Recent reports from Europe and North America are indicating declining trends in the environmental levels of these BFRs, especially PBDEs (Airaksinen et al. 2014, Kong et al. 2014). However, the stockpiles of electronic wastes (e-wastes) and waste electrical and electronic equipment (WEEE), which are important repositories of these pollutants, continue to pose serious threat to both the environment and public health in most developing countries. This is mainly due to the lack of appropriate technology for the recovery of precious and valuable materials from these obsolete e-waste materials. As a consequence, the recycling activities are often crudely undertaken without any consideration for the safety and health of the exposed workers. The generation and disposal of large waste stream of obsolete WEEE is particularly driven by the production of new and more sophisticated electronic products coupled with the growing desire to 
own modern electronic products. These lifestyle preferences are contributing to the thriving practice of international movement of e-wastes as exports to developing countries in the name of bridging the digital divide and this has been identified as the main route of e-waste disposal in most developed countries (Nnorom \&Osibanjo 2008). Despite the institutionalization of the international regulatory framework (Basel Convention) aimed to restrict the transboundary movement of e-wastes, the inflow of e-wastes into developing countries, especially within the continent of Africa, is still alarming. A survey conducted by the Basel Action Network (BAN) revealed that an estimated 60,000 metric tonnes of second-hand computer wares are imported annually into Nigeria through the Lagos port. The report further revealed that $25-75 \%$ of these obsolete computer hardware components are unusable junk that are either non-functional or unrepairable (Puckett et al. 2005). Although there have been no reported incidence of illegal e-wastes disposal in South Africa, several reported incidences of these illicit practices are common with other developing countries in Africa and Asia where these e-wastes eventually end up in landfill and open dumpsites (Daso et al. 2016).

It is worth mentioning that South Africa has been playing a leading role in the continent of Africa with respect to the monitoring of POPs in the environment. Although some of the past initiatives to screen for these pollutants in the environment had mainly been focused on certain organochlorine pesticides and polychlorinated biphenyls (PCBs) (Bouwman 2004), with little or no attention being paid to the recently listed POPs such as perfluorooctane sulfonate (PFOS) and its salts, perfluorooctanoic acid (PFOA), hexabromocyclododecane (HBCDD), amongst others. A comprehensive review on the environmental monitoring of BFRs in different environmental matrices in Africa, with a special focus on South Africa was recently published (Brits et al. 2016). The authors concluded that the analyses of various BFRs in different matrices were mainly performed at overseas laboratories, while only a few studies were fully conducted within the country.

Most landfill, especially in developing countries, were designed and constructed prior to the recognition of the potential health risks associated with exposure to the harmful persistent organic pollutants. Bearing this in mind, it is important to ensure that the current practice of co-disposal of e- 
wastes with other municipal wastes needs to be discouraged. In addition, the solid waste management practices are still poorly developed as many countries within this region are still practising open dumping system. Given the leaching potentials of these BFRs, especially the PBDEs under the prevailing climatic conditions, a great proportion of these pollutants can easily migrate into the underlying soil, and hence could have negative impact on the quality of the groundwater (Odusanya et al. 2009). In this regard, the seepage of landfill leachate into the groundwater may pose a serious threat to the health of the vast populations who depend on groundwater as their source of water supply.

Landfill leachate comprises dissolved humic substances, in addition to other toxic pollutants, and its composition can vary considerably from one region to the other. The infiltration of leachate into groundwater is particularly aggravated with old landfills which are not originally designed to receive e-waste and do not have appropriate liners or barriers to prevent any leachate leakage (Kiddee et al. 2014). In their study, Kiddee et al. (2014) highlighted the peculiarity of this unforeseen environmental challenge with both industrialised and developing countries as the promulgation of environmental legislations were generally at their infancy when most of these landfills were constructed. In South Africa, there are new requirements which must be met prior to the issuance of operational permits to landfill operators by the Department of Environmental Affairs. Under the new arrangements, sanitary landfill are required to be properly engineered with appropriate geo-membrane liners and the construction of monitoring wells to check for possible leakages in the event of liner damage or failure. In view of the aforementioned concerns, the need to foster an understanding on the environmental occurrence of these BFRs, especially in landfill leachate, and how it may possibly influence their transport and ultimate fate in the hydrogeological systems cannot be overemphasised. A number of studies have been conducted on the characterization of landfill leachate in South Africa (Daso et al. 2013, Odusanya et al. 2009, Olukunle et al. 2015). However, these studies have focused mainly on the occurrence of PBDEs in landfill leachate. Presently, there is still paucity of information on the occurrence of TBBPA and HBCDD in leachate samples from this region. Consequently, this study was 
aimed to evaluate the occurrence of some common BFRs in landfill leachate samples. In addition, an attempt was made to evaluate the possible influence of dissolved organic carbon on the concentrations of these pollutants in landfill leachate.

\section{Materials and methods}

\subsection{Chemicals and materials}

HPLC grade organic solvents ( $\mathrm{n}$-hexane, dichloromethane, isooctane and methanol) as well as LC-MS Ultra CHROMASOLV ${ }^{\circledR}$ water (with $0.1 \%$ formic acid) and formic acid $\left(\mathrm{HCO}_{2} \mathrm{H}\right)$ as an eluent additive for LC-MS were purchased from Sigma-Aldrich (Aston Manor, South Africa). Romil-UpS ${ }^{\text {TM }}$ ultrapure methanol (MeOH) as well as leucine encephalin was purchased from Microsep (JHB, South Africa). Surrogate standards $\left({ }^{13} \mathrm{C}\right.$-labelled BDE 77, 139 and 209) as well as unlabelled native PBDE congeners BDE-17, 28, 47, 100, 99, 154, 153, 183 and 209 were purchased from Wellington Laboratories (Ontario, Canada). Individual HBCDD standard for each isomer ( $\alpha, \beta$ and $\gamma$ ) and TBBPA standard were also purchased from Wellington Laboratories (Ontario, Canada). Pentachloronitrobenzene (PCNB) employed as internal standard was produced by Cambridge Isotope Laboratories (CIL) (Andover, MA, USA) and was locally supplied by Industrial Analytical (Pty) (Midrand, South Africa). Solid-phase extraction (SPE) cartridges (Supelco ENVI-18 ${ }^{\mathrm{TM}}$ ), Whatman filter paper (Grade 595) and anhydrous sodium sulphate (ACS grade) was supplied by Sigma-Aldrich (Aston Manor, South Africa), while silica gel was supplied by Merck (South Africa). High purity gases (Helium - 99.999\%; nitrogen 99.999\%) were purchased from by Afrox (Pty) Ltd. (Pretoria, South Africa).

\subsection{Sample collection and preparation}

A total of twenty-four (24) leachate samples were collected between May and July 2014 during the winter season from eight (8) landfill sites situated at different locations in Pretoria and Johannesburg, Gauteng Province, South Africa. Samples were collected into pre-cleaned $2.5 \mathrm{~L}$ amber bottles and were kept cooled with ice en-route to the laboratory. Two hundred millilitres of leachate sample was filtered 
under vacuum in triplicates. Prior to extraction for PBDEs analysis, the filtrate was spiked with known amount of the surrogate standards $\left({ }^{13} \mathrm{C}-\mathrm{BDE} 77,139\right.$ and 209) to monitor the recovery efficiency of the extraction method. The extraction was performed with ENVI-18 ${ }^{\mathrm{TM}}$ cartridge previously conditioned with $5 \mathrm{~mL}$ each of $\mathrm{n}$-hexane, dichloromethane, methanol and MilliQ water in this sequence. The flow rate of approximately one drop per second was maintained throughout the sample extraction. After the extraction, the SPE cartridges were vacuum dried for $45 \mathrm{~min}$. before the elution of the target compounds. PBDEs were eluted with $12 \mathrm{~mL}$ of $\mathrm{n}$-hexane:dichloromethane $(3: 1, \mathrm{v} / \mathrm{v})$, while TBBPA and the HBCDD isomers were eluted with $12 \mathrm{~mL}$ of dichloromethane:methanol $(4: 1, \mathrm{v} / \mathrm{v})$. The extracts were concentrated under a gentle stream of nitrogen to incipient dryness. The dried extracts were then reconstituted with $500 \mu \mathrm{L}$ of $100 \mathrm{ppb}$ internal standard (PCNB) solution prior to the instrumental analysis for PBDEs, while the extracts containing the HBCDD and TBBPA fraction were reconstituted in methanol.

\subsection{Instrumental analysis}

\subsubsection{Gas chromatography-mass spectrometry (GC-MS) for PBDE analysis}

In this study, the quantitative estimation of all the target compounds followed a previously described method (Daso et al. 2015), and was performed using an Ultra-trace 2010 Shimadzu GC equipped with QP2010 Ultra mass spectrometer operated in El mode. The target compounds were separated on a ZB-5 MS (15 m, $0.25 \mathrm{~mm}$ i.d., $0.25 \mu \mathrm{m}$ film thickness) high capillary GC column employing splitless injection technique. The MS acquisition was performed in selected ion monitoring (SIM) mode to improve the sensitivity of the instrument and also to overcome the inherent problems of interfering co-extractants during the analysis. For this purpose, a target ion and two reference ions were selected for each PBDE congener and the surrogate standards for their identification and quantification. The quantitation of the PBDE congeners was performed using an internal standard method where PCNB was employed as an internal standard. The resulting correlation co-efficient $\left(R^{2}\right)$ values obtained were greater than 0.997. The details of the selected target and reference ions for each PBDE congener as 
well as for the surrogate standards are presented in Supplementary Table S1, while the optimal conditions employed for the GC-EI-MS instrument are shown in Supplementary Table S2.

\subsubsection{Ultra-performance liquid chromatography-time-of-flight-mass spectrometry (UPLC-TOF- MS) for the analysis of HBCDD and TBBPA}

A Waters Acquity UPLC system equipped with a Waters BEH C18, $2.1 \mathrm{~mm} \times 100 \mathrm{~mm}, 1.7 \mu \mathrm{m}$ column was employed. The column temperature was set at $40^{\circ} \mathrm{C}$ and the flow rate was maintained at 0.3 $\mathrm{ml} / \mathrm{min}$. The mobile phase consisted of A: Water $0.1 \% \mathrm{HCO}_{2} \mathrm{H}$ and $\mathrm{B}: 85 \% \mathrm{MeOH}+0.1 \% \mathrm{HCO}_{2} \mathrm{H}$. A total run time of $10 \mathrm{~min}$. was used following a gradient elution method as follows: $0.00 \mathrm{~min}-85 \% \mathrm{~B} ; 2.00$ $\min -85 \% B ; 5.00 \mathrm{~min}-100 \% \mathrm{~B} ; 6.00 \mathrm{~min}-100 \% \mathrm{~B} ; 7.00 \mathrm{~min}-85 \% \mathrm{~B} ; 10.00 \mathrm{~min}-85 \% \mathrm{~B}$. The weak and strong wash solvents were $50 \% \mathrm{MeOH}$ and $100 \% \mathrm{MeOH}$, respectively. An injection volume of $5 \mu \mathrm{l}$ was used.

A Waters Synapt G2 equipped with an ESI source was used to acquire negative ion data in sensitivity mode and the entire system was driven by Masslynx software. Prior to sample analysis, the MS was calibrated through direct infusion of $5 \mathrm{mM}$ sodium formate solution at a flow rate of $20 \mu \mathrm{min}^{-1}$ and employment of the Intellistart functionality to a mass accuracy of typically $0.3 \mathrm{mDa}$ over the mass range of 100-1000 Da. Throughout all acquisitions, a $2 \mathrm{ng} \mathrm{hL}^{-1}$ solution of leucine encephalin was used as the lockspray solution that was constantly infused at a rate of $3 \mu \mathrm{l} \mathrm{min}{ }^{-1}$ through a separate orthogonal ESI probe so as to compensate for experimental drift in mass accuracy. The MS source parameters were set as follows: capillary $(\mathrm{kV})-2.8$; source temperature $\left({ }^{\circ} \mathrm{C}\right)-110$; sampling cone $(\mathrm{V})$ - 20; extraction cone (V) - 4; desolvation temperature $\left({ }^{\circ} \mathrm{C}\right)$ - 300; cone gas flow (L/Hr.) - 10.0; desolvation gas flow (L/Hr.) - 500.0.

Precursor mass spectra were acquired with a scan time of $0.5 \mathrm{sec}$ and an interscan time of $0.024 \mathrm{sec}$. Two separate functions were acquired. The first function collected continuum data over a mass range of $535-560 \mathrm{~m} / \mathrm{z}$ and employed an Enhanced Duty Cycle (EDC) mass of $542.7 \mathrm{~m} / \mathrm{z}$ so as to maximize sensitivity. The second function acquired data over a mass range of 550-660 m/z with an EDC mass of 
$640.6 \mathrm{~m} / \mathrm{z}$. Quanlynx software was used for analyte quantitation. The quantitation method employed a quantification trace of 542.73 and 640.63 for TBBPA and the HBCDD diastereoisomers, respectively, both with an absolute mass window of 0.1 Da. External calibration using the peak areas of each analyte alone was performed.

\subsubsection{Dissolved organic carbon (DOC) and physicochemical parameters determinations}

The DOC concentrations of filtered leachate samples were determined with an Apollo 900 Tekmar TOC analyser (Mason, Ohio USA). Each sample was carefully transferred into the $40 \mathrm{~mL}$ TOC vial with Teflon septum caps for analysis. Five calibration solutions of potassium hydrogen phthalate (KHP) with concentrations ranging from 1 to $25 \mathrm{ppm}$ were employed and the correlation co-efficient of the resulting curve exceeded 0.995. Finally, blank samples (de-ionised water) were also analysed during the analysis. The physicochemical parameters $(\mathrm{pH}$, electrical conductivity, and dissolved oxygen content) were analysed using a HACH HQ40D portable multi-meter instrument (Loveland, USA), while the total suspended solids was determined by gravimetric technique.

\subsection{Quality control and quality assurance}

Higher brominated PBDE congeners are photo-sensitive, hence amber coloured containers were used throughout this study and where these were not available, sample containers were wrapped with aluminium foil. To assess possible contamination during sample preparation, reagent and procedural blanks were analysed with the samples. Detectable levels of target compounds found in the blanks were deducted from results obtained for each sample. The recoveries of the spiked ${ }^{13} \mathrm{C}$-labelled PBDE surrogate standards ranged from $89\left({ }^{13} \mathrm{C}-\mathrm{BDE} 209\right)$ to $119 \%\left({ }^{13} \mathrm{C}-\mathrm{BDE} 77\right)$. Due to the unavailability of isotopically labelled TBBPA and HBCDD while this study was undertaken, the samples could not be spiked prior to extraction. However, a laboratory matrix (filtered leachate: MilliQ water, 1:4, v/v) was prepared to assess the recoveries of these compounds in the aqueous samples through spiking experiments where triplicate spiked and unspiked samples were analysed. The recoveries of these 
compounds in the filtered samples were $86 \%, 108 \%, 95 \%$ and $63 \%$ for $\alpha-H B C D D, \beta-H B C D D, \gamma-H B C D D$ and TBBPA, respectively.

\subsection{Multivariate statistical analysis}

Pairwise correlation analysis was performed with JMP ${ }^{\circledR} 10$ (SAS Institute Inc., USA) to establish the relationship between the different variables. For this purpose, concentrations of target compounds below the detection limit were assigned half of their LOQ values and $\alpha$ value was set at 0.05 throughout the statistical analysis.

\section{Results and discussion}

\subsection{Physicochemical profile of leachate samples}

The investigated landfills mainly receive general waste materials with varying quantities and compositions. As a consequence, the physicochemical profiles of the resulting leachate from these sites are expected to be highly variable. The physicochemical profiles of the leachate samples investigated in this study are summarized in Table 1 . The observed $\mathrm{pH}$ values indicated that the leachate samples were mostly slightly alkaline, except for landfill site 4, where it was slightly acidic. The electrical conductivity provides useful information on the relative amount of soluble salts in a solution. Interestingly, all the leachate samples contained considerably high salt content possibly reflecting the rapid decomposition of waste materials within the landfill.

Aqueous waste streams with low dissolved oxygen (DO) content portend a huge ecological risk to the receiving water bodies. The influx of such waste streams could significantly affect the survival rate of aquatic fauna since their metabolic activities require considerable amount of dissolved oxygen. Most of the leachate samples had considerably low dissolved oxygen concentration $(<4.45 \mathrm{mg} \mathrm{DO} / \mathrm{L})$, except 
Table 1: The physicochemical profile indicating the mean ( \pm standard deviation) of various parameters for each landfill site

\begin{tabular}{|c|c|c|c|c|c|}
\hline $\begin{array}{l}\text { Sampling sites } \\
\text { (GPS coordinates) }\end{array}$ & pH & $\begin{array}{l}\text { Electrical conductivity } \\
(\mathrm{mS} / \mathrm{cm})\end{array}$ & Dissolved oxygen (mg/L) & $\begin{array}{l}\text { Dissolved organic carbon } \\
(\mathrm{mg} / \mathrm{L})\end{array}$ & Suspended solids (mg/L) \\
\hline $\begin{array}{l}\text { 1. (S 26 } 6^{\circ} 16^{\prime} 53.87^{\prime \prime}, \\
\left.\text { E } 27^{\circ} 55^{\prime} 24.48^{\prime \prime}\right)\end{array}$ & $8.22 \pm 0.01$ & $20.87 \pm 0.01$ & $0.46 \pm 0.03$ & $34.9 \pm 3.21$ & $227 \pm 90.2$ \\
\hline $\begin{array}{l}\text { 2. (S } 26^{\circ} 13^{\prime} 59.03^{\prime \prime}, \\
\left.\text { E } 28^{\circ} 02^{\prime} 14.77^{\prime \prime}\right)\end{array}$ & $8.55 \pm 0.02$ & $28.83 \pm 0.06$ & $0.06 \pm 0.02$ & $48.7 \pm 6.35$ & $846 \pm 111$ \\
\hline $\begin{array}{r}\text { 3. (S } 26^{\circ} 02^{\prime} 30.35^{\prime \prime}, \\
\left.\text { E } 28^{\circ} 10^{\prime} 04.58^{\prime \prime}\right)\end{array}$ & $7.83 \pm 0.01$ & $17.98 \pm 0.02$ & $0.33 \pm 0.01$ & $42.7 \pm 2.30$ & $109 \pm 29.5$ \\
\hline $\begin{array}{l}\text { 4. (S } 25^{\circ} 34^{\prime} 57^{\prime \prime}, \\
\left.\text { E } 27^{\circ} 59^{\prime} 05^{\prime \prime}\right)\end{array}$ & $6.87 \pm 0.04$ & $1.08 \pm 0.001$ & $3.32 \pm 0.21$ & $34.8 \pm 0.98$ & $616 \pm 444$ \\
\hline $\begin{array}{l}\text { 5. (S } 25^{\circ} 49^{\prime} 54.12^{\prime \prime}, \\
\text { E } 28^{\circ} 16^{\prime} 7.68^{\prime \prime} \text { ) }\end{array}$ & $7.26 \pm 0.05$ & $0.41 \pm 0.00$ & $7.20 \pm 0.05$ & $11.9 \pm 1.16$ & $332 \pm 184$ \\
\hline $\begin{array}{l}\text { 6. (S } 25^{\circ} 31^{\prime} 37^{\prime \prime}, \\
\left.\text { E } 28^{\circ} 06^{\prime} 32^{\prime \prime}\right)\end{array}$ & $7.85 \pm 0.05$ & $14.23 \pm 0.01$ & $0.06 \pm 0.02$ & $60.4 \pm 4.32$ & $1360 \pm 484$ \\
\hline $\begin{array}{l}\text { 7. (S } 26^{\circ} 0^{\prime} 28.8^{\prime \prime}, \\
\left.\text { E } 27^{\circ} 51^{\prime} 52.56^{\prime \prime}\right)\end{array}$ & $7.02 \pm 0.06$ & $1.00 \pm 0.00$ & $3.95 \pm 0.34$ & $52.1 \pm 3.42$ & $163 \pm 94.4$ \\
\hline $\begin{array}{l}\text { 8. (S } 25^{\circ} 39^{\prime} 02^{\prime \prime}, \\
\left.\text { E } 28^{\circ} 11^{\prime} 03^{\prime \prime}\right)\end{array}$ & $7.12 \pm 0.06$ & $0.85 \pm 0.001$ & $4.43 \pm 0.42$ & $52.7 \pm 1.14$ & $243 \pm 128$ \\
\hline
\end{tabular}


for landfill site 5, which had an average DO value of $7.20 \mathrm{mg} \mathrm{L}^{-1}$. The highest concentration of suspended solids $(1360 \pm 484)$ was observed at landfill site 6 . The elevated levels of the suspended solids could be due to the influence of construction activities (road construction) in close proximity to the leachate ponds where the samples were collected. Suspended solids play an important role in the transport and hydrogeological distribution of organic pollutants in water systems. Many organic pollutants are known to exhibit strong affinity towards fine suspended particulates in water column, thus contributing to their rapid dispersion as well as deposition within the water systems. The amount of dissolved organic carbon (DOC) was relatively similar for all the leachate samples investigated. This could be a reflection of similar percentage composition of biodegradable waste materials being handled by each landfill site. The possible influence of DOC and its association with the target compounds investigated in this study were discussed in sub-section 3.3. In general, the physicochemical profiles of the leachate samples had similar attributes to that previously classified as methanogenic landfill site (Mårtensson et al. 2007).

\subsection{Occurrence of target compounds in leachate samples}

This preliminary study provides useful information on the occurrence and concentrations of commonly used BFRs as well as PBDEs in leachate samples in the most industrialized region of South Africa. The detailed results of the concentrations of the target BFRs are presented in Table 2. In the case of PBDEs, only the lower brominated congeners were detected in the investigated samples. None of the higher brominated congeners $\left(>\mathrm{Br}_{6}\right)$ except BDE 154 , was detected in the leachate samples. Kwan et al. (2013) attributed the substantial proportion of PBDE congeners found in the dissolved phase of leachate samples to the relatively high concentrations of dissolved organic carbon (DOC) relative to the particulate organic carbon (POC) levels. In the present study, this assertion cannot be fully ascertained because only the DOC concentrations of leachate samples from all the eight (8) landfill sites were assessed. 
Table 2: Detailed summary of the concentrations $(\mu \mathrm{g} / \mathrm{L})$ of target compounds in landfill leachate samples

\begin{tabular}{|c|c|c|c|c|c|c|c|c|c|c|c|c|c|c|c|}
\hline $\begin{array}{l}\text { Sampling } \\
\text { sites }\end{array}$ & & BDE 17 & BDE 28 & BDE 47 & BDE 100 & BDE 99 & BDE 154 & BDE 153 & BDE 183 & BDE 209 & ${ }^{*}$ EPBDES & $\alpha-\mathrm{HBCD}^{+}$ & $\beta-\mathrm{HBCD}^{+}$ & $\gamma-\mathrm{HBCD}^{+}$ & TBBPA $^{+}$ \\
\hline \multirow[t]{4}{*}{1} & Mean & 0.14 & 0.05 & 0.73 & $<0.01$ & 0.26 & $<0.04$ & $<0.17$ & $<0.52$ & $<1.22$ & 0.18 & $<0.03$ & $<0.05$ & $<0.03$ & $<0.82$ \\
\hline & \%RSD & 57.1 & 140 & 5.48 & - & 42.3 & - & - & - & - & & - & - & - & - \\
\hline & Min. & $<0.03$ & $<0.03$ & 0.69 & $<0.01$ & 0.14 & $<0.04$ & $<0.17$ & $<0.52$ & $<1.22$ & & $<0.03$ & $<0.05$ & $<0.03$ & $<0.82$ \\
\hline & Max. & 0.24 & 0.14 & 0.76 & $<0.01$ & 0.36 & $<0.04$ & $<0.17$ & $<0.52$ & $<1.22$ & & $<0.03$ & $<0.05$ & $<0.03$ & $<0.82$ \\
\hline \multirow[t]{4}{*}{2} & Mean & 0.19 & 0.20 & 0.74 & 0.23 & 0.24 & $<0.04$ & $<0.17$ & $<0.52$ & $<1.22$ & 0.21 & $<0.03$ & $<0.05$ & $<0.03$ & $<0.82$ \\
\hline & \%RSD & 5.26 & 35.0 & 14.9 & 82.6 & 50.0 & - & - & - & - & & - & - & - & - \\
\hline & Min. & $<0.03$ & 0.10 & 0.57 & $<0.04$ & 0.11 & $<0.04$ & $<0.17$ & $<0.52$ & $<1.22$ & & $<0.03$ & $<0.05$ & $<0.03$ & $<0.82$ \\
\hline & Max. & 0.34 & 0.28 & 0.91 & 0.53 & 0.43 & $<0.04$ & $<0.17$ & $<0.52$ & $<1.22$ & & $<0.03$ & $<0.05$ & $<0.03$ & $<0.82$ \\
\hline \multirow[t]{4}{*}{3} & Mean & $<0.01$ & $<0.01$ & $<0.01$ & $<0.01$ & 0.11 & $<0.04$ & $<0.17$ & $<0.52$ & $<1.22$ & 0.04 & $<0.03$ & $<0.05$ & $<0.03$ & $<0.82$ \\
\hline & \%RSD & - & - & - & - & 36.4 & - & - & - & - & & - & - & - & - \\
\hline & Min. & $<0.01$ & $<0.01$ & $<0.01$ & $<0.01$ & 0.05 & $<0.04$ & $<0.17$ & $<0.52$ & $<1.22$ & & $<0.03$ & $<0.05$ & $<0.03$ & $<0.82$ \\
\hline & Max. & $<0.01$ & $<0.01$ & $<0.01$ & $<0.01$ & 0.17 & $<0.04$ & $<0.17$ & $<0.52$ & $<1.22$ & & $<0.03$ & $<0.05$ & $<0.03$ & $<0.82$ \\
\hline \multirow[t]{4}{*}{4} & Mean & $<0.01$ & $<0.01$ & 0.31 & 0.56 & 0.57 & $<0.04$ & $<0.17$ & $<0.52$ & $<1.22$ & 0.19 & $<0.03$ & $<0.05$ & 2.17 & $<0.82$ \\
\hline & \%RSD & - & - & 113 & 114 & 15.8 & - & - & - & - & & - & - & 111 & - \\
\hline & Min. & $<0.01$ & $<0.01$ & 0.11 & $<0.04$ & 0.44 & $<0.04$ & $<0.17$ & $<0.52$ & $<1.22$ & & $<0.03$ & $<0.05$ & $<0.03$ & $<0.82$ \\
\hline & Max. & $<0.01$ & $<0.01$ & 0.62 & 0.98 & 0.70 & $<0.04$ & $<0.17$ & $<0.52$ & $<1.22$ & & $<0.03$ & $<0.05$ & 4.75 & $<0.82$ \\
\hline \multirow[t]{4}{*}{5} & Mean & $<0.01$ & $<0.01$ & $<0.01$ & 1.24 & 0.65 & 0.16 & $<0.17$ & $<0.52$ & $<1.22$ & 0.27 & $<0.03$ & $<0.05$ & 0.58 & $<0.82$ \\
\hline & \%RSD & - & - & - & 76.6 & 44.6 & 200 & - & - & - & & - & - & 173 & - \\
\hline & Min. & $<0.01$ & $<0.01$ & $<0.01$ & 0.59 & 0.34 & $<0.12$ & $<0.17$ & $<0.52$ & $<1.22$ & & $<0.03$ & $<0.05$ & $<0.03$ & $<0.82$ \\
\hline & Max. & $<0.01$ & $<0.01$ & $<0.01$ & 2.66 & 0.99 & 0.64 & $<0.17$ & $<0.52$ & $<1.22$ & & $<0.03$ & $<0.05$ & 1.75 & $<0.82$ \\
\hline \multirow[t]{4}{*}{6} & Mean & 0.68 & 0.09 & 0.99 & 0.49 & 1.94 & $<0.04$ & $<0.17$ & $<0.52$ & $<1.22$ & 0.48 & $<0.03$ & $<0.05$ & 2.50 & $<0.82$ \\
\hline & \%RSD & 8.82 & 44.4 & 66.7 & 196 & 212 & - & - & - & - & & - & - & 98.5 & - \\
\hline & Min. & 0.64 & $<0.03$ & 0.62 & $<0.04$ & $<0.07$ & $<0.04$ & $<0.17$ & $<0.52$ & $<1.22$ & & $<0.03$ & $<0.05$ & 0.50 & $<0.82$ \\
\hline & Max. & 0.72 & 0.13 & 1.55 & 1.35 & 5.81 & $<0.04$ & $<0.17$ & $<0.52$ & $<1.22$ & & $<0.03$ & $<0.05$ & 5.25 & $<0.82$ \\
\hline \multirow[t]{4}{*}{7} & Mean & $<0.01$ & $<0.01$ & 0.82 & 0.33 & 0.42 & $<0.04$ & $<0.17$ & $<0.52$ & $<1.22$ & 0.19 & $<0.03$ & $<0.05$ & 2.58 & $<0.82$ \\
\hline & \%RSD & - & - & 81.7 & 18.2 & 97.6 & - & - & - & - & & - & - & 96.9 & - \\
\hline & Min. & $<0.01$ & $<0.01$ & $<0.03$ & $<0.04$ & $<0.07$ & $<0.04$ & $<0.17$ & $<0.52$ & $<1.22$ & & $<0.03$ & $<0.05$ & $<0.03$ & $<0.82$ \\
\hline & Max. & $<0.01$ & $<0.01$ & 1.70 & 0.55 & 0.92 & $<0.04$ & $<0.17$ & $<0.52$ & $<1.22$ & & $<0.03$ & $<0.05$ & 5.00 & $<0.82$ \\
\hline \multirow[t]{4}{*}{8} & Mean & $<0.01$ & $<0.01$ & $<0.01$ & 0.31 & 0.24 & $<0.04$ & $<0.17$ & $<0.52$ & $<1.22$ & 0.07 & $<0.03$ & $<0.05$ & 0.25 & $<0.82$ \\
\hline & \%RSD & - & - & - & 106 & 87.5 & - & - & - & - & & - & - & 173 & - \\
\hline & Min. & $<0.01$ & $<0.01$ & $<0.01$ & $<0.04$ & $<0.07$ & $<0.04$ & $<0.17$ & $<0.52$ & $<1.22$ & & $<0.03$ & $<0.05$ & $<0.03$ & $<0.82$ \\
\hline & Max. & $<0.01$ & $<0.01$ & $<0.01$ & 0.87 & 0.61 & $<0.04$ & $<0.17$ & $<0.52$ & $<1.22$ & & $<0.03$ & $<0.05$ & 0.75 & $<0.82$ \\
\hline
\end{tabular}


The distribution of PBDEs in aqueous media is particularly influenced by both the presence of suspended solids and DOC. In general, the individual partitioning behaviours of each PBDE congener differs due to their differential solubility in aqueous media. For PBDEs, solubility generally decreases with increasing number of bromine. Hence, the lower brominated congeners such as BDE 28 and 47 tend to preferentially associate with the dissolved phase rather than the adsorbed phase. Typically, these behaviours are often dependent on the relative abundance of DOC in the aqueous media. By implication, the preferential partitioning of BDE 47 and other lower PBDE congeners into the dissolved phase suggests that these congeners would be more mobile and more readily bioavailable, thus contributing to groundwater contamination (Gorgy et al. 2010). In addition, the presence of dissolved organic matter (DOM) in leachate may rapidly facilitate the leaching of PBDEs from treated products. By so doing, the solubility of hydrophobic BFRs in aqueous media may significantly increase via different mechanisms such as cosolvency, hydrolysis, catalysis and complex formation between DOM and BFRs (Choi et al. 2009, Kim et al. 2006, Li et al. 2014). Besides the established influences of both DOC and suspended solids on PBDEs levels in leachate samples, the possible influence of trace metals and other secondary contaminants on their concentrations in this matrix has been highlighted (Olukunle et al. 2015). In a complex matrix such as landfill leachate, the possibility of complex formation between PBDEs and other organic and inorganic micro-pollutants is highly feasible. Although this assertion is yet to be scientifically proven, future studies need to be focussed on this possibility.

The occurrence of the HBCDD isomers was somewhat different from that observed for the PBDEs. Despite the relatively high solubility of both $\alpha-\operatorname{HBCDD}\left(48.8 \mu \mathrm{g} \mathrm{L}^{-1}\right)$ and $\beta-\operatorname{HBCDD}\left(14.7 \mu \mathrm{g} \mathrm{L}^{-1}\right)$ according to Covaci et al. (2006), none of these isomers were detected in the investigated samples collected from all the eight (8) landfill sites. Only $\mathrm{Y}$-HBCDD was detected in 5 out of the 8 investigated landfill sites, although this isomer was present at extremely low concentrations $\left(n g \mathrm{~L}^{-1}\right)$. The observed trend 
may be indicative of the composition of each of the HBCDD isomers in the technical mixture. According to Covaci et al. (2006), the technical HBCDD is mainly dominated by the $\mathrm{\gamma}$-HBCDD constituting up to $75-89 \%$ of the entire mixture. The other two major isomers are often present at low concentrations where they constitute about $10-13 \%$ and $1-12 \%$ composition for $\alpha$-HBCDD and $\beta-H B C D D$, respectively. In addition, the prevalence of the $\mathrm{\gamma}$-HBCDD may also be due to its extremely low solubility (2.1 $\left.\mu \mathrm{g} \mathrm{L}^{-1}\right)$, and its strong affinity to suspended solids in aqueous media. Furthermore, its detection in the leachate samples at most of the landfill sites may be indicative of the widespread usage of HBCDD in this region, although there is no documented information on its production and consumption pattern in South Africa.

Unlike PBDEs and HBCDD which are neutral compounds, TBBPA may exist in both ionic and non-ionic forms depending on the $\mathrm{pH}$ of the aqueous medium in which it is present. In this study, TBBPA was not detected in the investigated landfill leachate. TBBPA is a polar compound having $\mathrm{pK}_{\mathrm{a} 1}$ and $\mathrm{pK}_{\mathrm{a} 2}$ values of 7.5 and 8.5 , respectively (EHC-172 1995). This implies that in neutral environments, as it is the case for leachate samples investigated in this study (pH range: 6.83-8.57), a substantial part of the TBBPA would be present in its dissociated form (Covaci et al. 2009). Additionally, TBBPA exhibits different physicochemical properties such as water solubility, 1-octanol-water partition coefficient (Kow), Henry's law constant $\left(H_{w}\right)$, vapour pressure, amongst others. These properties are important in understanding its environmental occurrence, distribution and its ultimate chemical fate. Specifically, the phenolic ionization of TBBPA has been identified as the key factor contributing to the observed differences in its physicochemical properties in aqueous media (Kuramochi et al. 2008). The combination of these factors may have contributed to its non-detection in the leachate samples investigated in this study. To have a clear reflection of its environmental occurrence, it is important that its distinct physicochemical characteristics are taken into consideration while developing appropriate chromatographic methods for its quantification, particularly in aqueous environmental matrices. 
Municipal solid waste landfill (MSWL) sites are important repositories of diverse environmental contaminants. The characterization of leachate derived from these sites is necessary not only because it is critical to assess the levels of these pollutants but to also determine their degree of occurrence in this complex environmental matrix. In order to be able to deploy cost-effective remediation techniques for pollutant removal in polluted environments, these information are often required. PBDEs are ubiquitous pollutants and their environmental persistence, toxicity, bioaccumulation potential as well as their capability to undergo long-range atmospheric transport are a serious cause for concern. Among the BFRs monitored in the study, only PBDEs were detected in all the landfill sites investigated. Their continued presence in landfill leachate despite the global restriction on the use and production of certain technical formulations (penta-BDE and octa-BDE) is worrisome. This probably suggests that disposed products previously treated with these chemicals which are stored up in different landfill sites may continue to pose serious threat to the environment and human health if efforts are not geared towards ensuring a proper management of landfill leachate.

Of all the landfill sites investigated, landfill site 6 had the highest mean of total PBDEs $\left(0.48 \mu \mathrm{g} \mathrm{L}^{-1}\right)$ in the dissolved phase, where BDE 99 was the dominant congener. Generally, the congeners representing the penta-BDE formulation ( $B D E 47,99$ and 100) were the most dominant in the investigated landfill leachate. The prevalence of these lower brominated congeners is of serious concern due to their capability to elicit a number of adverse health effects in aquatic organisms. In particular, zebrafish (Danio rerio) were exposed to ecologically relevant concentrations of BDE-47, although it was administered through the diet at levels that were similar to those observed in the present study. Exposure of zebrafish to these concentrations of BDE-47 were reported to cause alteration of locomotion behaviour (Chou et al. 2010), disruption of axonal growth and motor behaviour in developing zebrafish (Chen et al. 2012), and the disruption of the hypothalamic-pituitarythyroid axis which primarily functions to maintain normal, circulating levels of thyroid hormone that is essential for the biological function of all tissues, including brain development; regulation of 
cardiovascular, bone, and liver function; food intake; and energy expenditure amongst others (Chan \&Chan 2012).

With respect to the occurrence of the HBCDD in the leachate samples, none of the isomers was detected at landfill sites 2 and 3. Incidentally, these two sites receive relatively high proportion of industrial wastes as well as incineration residues of combustible and incombustible waste materials (Olukunle et al. 2015). The non-detection of HBCDD in these sites may be due to the possible thermal degradation of the treated polymers during the pyrolytic process. Furthermore, both $\alpha-H B C D D$ and $\beta-$ HBCDD were also not detected at landfill sites 5, 6 and 7, only the gamma isomer was detected at these sites. The predominance of the $\mathrm{\gamma}$-HBCDD in different environmental samples (Letcher et al. 2015, Xiang et al. 2015) and that of $\alpha$-HBCDD in biological matrices (Ryan \&Rawn 2014, Tang et al. 2015) have been established. TBBPA, on the other hand, is a reactive BFR that is covalently bound to the polymeric material to which it has been applied. Consequently, its leaching from treated products is expected to be limited as compared to the other additive BFRs (PBDEs and HBCDD). The aforementioned characteristics may, therefore, partly explain the occurrence of TBBPA in leachate samples in the present study.

\subsection{The influence of dissolve organic carbon (DOC) on the targeted BFRs in landfill leachate}

The environmental occurrence of organic pollutants can be greatly influenced by the presence of DOC and other associated factors. In most cases, higher DOC levels may result in correspondingly high organic pollutant's concentration in aqueous matrices. In this present study, the association between the target compounds and DOC in leachate samples from all the landfill sites were statistically evaluated. With respect to the correlation of DOC with targeted BFRs in the investigated landfill leachate samples, no significant correlation exists between BDE 153, BDE 183, BDE 209, $\alpha$-HBCDD, $\beta$ HBCDD, TBBPA and DOC. However, there were weak to moderate positive correlations $\left(0.62>R^{2}>0.17\right)$ between DOC and other target compounds except for BDE 100, where a moderate negative relationship $\left(R^{2}=-0.4060, P=0.2783\right)$ was observed. In a related study, PBDEs, PFCs and total organic 
carbon (TOC) levels in leachate samples were also reported to show weak positive correlation $\left(R^{2}<0.28\right)$ (Li et al. 2012). Considering the lipophilic properties of the targeted compounds, which may possibly contribute to their enhanced leachability in the presence of dissolved organic carbon (Choi et al. 2009, Kim et al. 2006, Osako et al. 2004). It was expected that the measured DOC in the present study would show strong positive correlations with these compounds. On the contrary, the expected relationships were not established possibly because of the complexity and heterogeneity of the leachate samples investigated. In their work, Li et al. (2012) identified a number of factors such as waste composition, landfill soil properties, rainwater chemistry, temperature within the landfill, sample collection methodologies, amongst others, that could potentially influence the concentrations of organic pollutants and their possible interactions with each other in landfill leachate.

\subsection{Comparison with other studies}

Generally, there is limited information on the levels of the investigated BFRs, particularly TBBPA and HBCDD in different environmental matrices in most developing countries, particularly in Africa. Nonetheless, the global comparison of the findings from the present study further confirms the ubiquitous distribution of the targeted BFRs, especially the PBDEs. As shown in Table 3, the sum PBDEs in the present study were generally higher than those previously reported for raw and treated leachate in China, Japan and South Africa (Huang et al. 2013, Odusanya et al. 2009, Osako et al. 2004), but were similar to those reported for some Chinese landfill sites (Li et al. 2014), while the reported levels of the sum PBDEs for some Australian and South African landfill sites (Daso et al. 2013, Gallen et al. 2016) were significantly higher than those observed in the present study. Furthermore, the levels of HBCDD observed in the present study were also generally higher than those previously reported. A number of interrelated factors may be responsible for the observed geographical differences in the measured levels of the targeted BFRs in landfill leachate. First of all, the waste management practices such as the re-use, recovery and recycling of valuable components of solid wastes prior to their disposal in landfills could significantly influence their environmental occurrence. For instance, the 
recycling of plastics and other valuable materials, which may have been treated with BFRs, is still in its infant stage in South Africa. Whereas, in countries such as Japan, these materials are often recycled (Odusanya et al. 2009), thus reducing the volume of BFR-treated materials which eventually end up in the solid waste treatment facilities.

Other factors such as socioeconomic indices and population growth may significantly influence the levels of BFRs in landfill leachate. Countries with moderate population and whose inhabitants have higher purchasing power and better economic opportunities can afford to acquire newer consumer products with no or less percentage of the "legacy" BFRs. In contrast, the high population of the developing countries, which is aptly characterized with limited or low purchasing power and poor economic opportunities provides impetus for preference to second-hand and obsolete electronic gadgets and other consumer products. Incidentally, these products are often short-lived, and they often end up in landfill and dumpsites. Finally, the prevailing environmental conditions in different geographical regions can determine the extent to which BFRs are released from previously treated materials dumped in dumpsites or landfills. Given the relatively high humidity and temperature in the tropical regions, it is expected that the rate of biodegradation would be higher than in the temperate regions. As a consequence, the amount of DOC in landfill leachate, which may be influenced by other factors such as the age of the landfill and waste composition, is expected to be higher than in the temperate regions. As previously indicated, the presence of DOC could therefore significantly influence the rate at which BFRs are released from the landfilled waste materials.

\section{Conclusions}

Among the BFRs investigated in this study, PBDEs were the most prevalent in the analysed leachate samples. Some targeted BFRs, including $\alpha-\mathrm{HBCDD}, \beta-\mathrm{HBCDD}$ as well as TBBPA were not detected in the leachate samples investigated. Similarly, the higher brominated PBDE congeners ( $\mathrm{Br}>6)$, except 
Table 3: Comparison of brominated flame retardants levels $(\mathrm{ng} / \ell)$ in landfill leachate with other studies around the world

\begin{tabular}{|c|c|c|c|c|c|c|}
\hline Location & Nature of matrix & TOC $^{\mathrm{a}} / \mathrm{DOC}^{\mathrm{b}} /$ COD $^{\mathrm{c}}$ & IPBDE $^{\mathrm{d}}$ & HBCDD & TBBPA & References \\
\hline \multirow[t]{2}{*}{ China } & Raw leachate & $2920-33600^{c}$ & $4.0-351$ & - & - & Li et al. 2014 \\
\hline & & $608-9328^{b}$ & & & & \\
\hline \multirow[t]{2}{*}{ Japan } & Raw/treated & $4-560^{a, e}$ & $\mathrm{nd}-4.00$ & - & n.d -620 & Osako et al., 2004 \\
\hline & leachate & $1-580^{c, e}$ & & & & \\
\hline South Africa & Raw leachate & $210-412^{c}$ & $8.39-54.8$ & - & - & Odusanya et al., 2009 \\
\hline Canada & Raw leachate & NR & $0.03-1020$ & - & - & Li et al., 2012 \\
\hline South Africa & Raw leachate & NA & $0.04-2560$ & - & - & Daso et al., 2013 \\
\hline China & Treated leachate & NA & $2.50-12.0$ & - & - & Huang et al., 2013 \\
\hline South Africa & Raw leachate & NA & - & $0.0048-0.04$ & - & Olukunle et al., 2015 \\
\hline Australia & Raw leachate & NA & $0.06-1600$ & n.d -9.3 & - & Gallen et al., 2016 \\
\hline South Africa & Raw leachate & $31-63^{b}$ & $70.0-480$ & n.d -5.25 & n.d & This study \\
\hline
\end{tabular}

${ }^{a}$ TOC - total organic carbon (mg/L); ${ }^{b} \mathrm{DOC}$ - dissolved organic carbon (mg/L); ${ }^{\mathrm{C} C O D}$ - chemical oxygen demand (mg/L); ${ }^{\mathrm{d}}-\mathrm{represents} \mathrm{the} \mathrm{sum} \mathrm{of} \mathrm{PBDE} \mathrm{congeners,} \mathrm{including}$ $\mathrm{BDE}$ 209, in most cases; ${ }^{\text {e }}$ - reported values for raw and treated leachate; NR - not reported; NA - not analysed. 
for BDE 154 were also not detected. However, the lower brominated PBDE congeners were frequently detected possibly due to their relatively high water solubility. Incidentally, majority of the landfill investigated in this study are not lined with geo-membrane and there are no on-site landfill leachate treatment facilities for most of the landfill sites. Consequently, it is highly probable that contamination of nearby water bodies, surface and groundwater sources, could be very common, although these water bodies were not analysed for the BFRs reported in the present study. Considering the toxicity of the lower PBDE congeners, especially BDE 47 and BDE 99, which are also the predominant congeners observed in the leachate samples, there is an urgent need to apply adequate measures to safeguard the environment and public health from possible adverse effects of these toxic pollutants. In this study, no significant correlation exists between BDE 153, BDE 183, BDE 209, $\alpha-H B C D D, \beta-$ HBCDD, TBBPA and DOC. However, there were weak to moderate positive correlations $\left(0.62>R^{2}>0.17\right)$ between DOC and other target compounds except for BDE 100, where a moderate negative relationship $\left(R^{2}=-0.4060, P=0.2783\right)$ was observed. Given the lipophilic properties of the BFRs investigated in this study, it was envisaged that DOC would show strong positive correlations with these compounds. On the contrary, DOC only showed weak to moderate positive correlations with some of the target compounds. Landfill leachate is a complex matrix, as a result, other factors which are not adequately addressed in this study may have influenced the relationships between DOC and the target compounds in this matrix.

\section{Acknowledgements}

The authors would like to acknowledge the management of Tshwane University of Technology (TUT), Pretoria for providing laboratory facilities and other logistics. We are also grateful to the management of the University of Pretoria for the Postdoctoral funding offered to AP Daso from the Vice Chancellor's Postdoctoral programme. The technical assistance offered by Ms IV Sibiya (TUT) and the LC-MS unit of the Department of Chemistry, University of Pretoria during the sample collection and instrumental analysis, respectively, are gratefully acknowledged. 


\section{References}

Airaksinen R, Hallikainen A, Rantakokko P, Ruokojärvi P, Vuorinen PJ, Parmanne R, Verta M, Mannio J, Kiviranta $H$ (2014): Time trends and congener profiles of PCDD/Fs, PCBs, and PBDEs in Baltic herring off the coast of Finland during 1978-2009. Chemosphere 114, 165-171

Bouwman H (2004): South Africa and the Stockholm convention on persistent organic pollutants. South African Journal of Science 100, 323-328

Brits M, de Vos J, Weiss JM, Rohwer ER, de Boer J (2016): Critical review of the analysis of brominated flame retardants and their environmental levels in Africa. Chemosphere 164, 174-189

Chan WK, Chan KM (2012): Disruption of the hypothalamic-pituitary-thyroid axis in zebrafish embryo-larvae following waterborne exposure to BDE-47, TBBPA and BPA. Aquatic Toxicology 108, 106-111

Chen X, Huang C, Wang X, Chen J, Bai C, Chen Y, Chen X, Dong Q, Yang D (2012): BDE-47 disrupts axonal growth and motor behavior in developing zebrafish. Aquatic Toxicology 120-121, 35-44

Choi K-I, Lee S-H, Osako M (2009): Leaching of brominated flame retardants from TV housing plastics in the presence of dissolved humic matter. Chemosphere 74, 460-466

Chokwe T, Okonkwo J, Sibali L, Ncube E (2015): Alkylphenol ethoxylates and brominated flame retardants in water, fish (carp) and sediment samples from the Vaal River, South Africa. Environ Sci Pollut Res 22, 11922-11929

Chou C-T, Hsiao Y-C, Ko F-C, Cheng J-O, Cheng Y-M, Chen T-H (2010): Chronic exposure of 2,2',4,4'tetrabromodiphenyl ether (PBDE-47) alters locomotion behavior in juvenile zebrafish (Danio rerio). Aquatic Toxicology 98, 388-395

Covaci A, Gerecke AC, Law RJ, Voorspoels S, Kohler M, Heeb NV, Leslie H, Allchin CR, de Boer J (2006): Hexabromocyclododecanes (HBCDs) in the environment and humans: a review. Environmental science \& technology 40, 3679-3688

Covaci A, Voorspoels S, Abdallah MA-E, Geens T, Harrad S, Law RJ (2009): Analytical and environmental aspects of the flame retardant tetrabromobisphenol-A and its derivatives. Journal of Chromatography A 1216, 346-363

Daso A, Fatoki O, Odendaal J, Olujimi O (2013): Polybrominated diphenyl ethers (PBDEs) and 2,2',4,4',5,5'hexabromobiphenyl (BB-153) in landfill leachate in Cape Town, South Africa. Environ Monit Assess $185,431-439$

Daso AP, Fatoki OS, Odendaal JP, Okonkwo JO (2010): A review on sources of brominated flame retardants and routes of human exposure with emphasis on polybrominated diphenyl ethers. Environmental Reviews $18,239-254$

Daso AP, Okonkwo JO, Jansen R, Forbes PB, Kotzé A, Rohwer ER (2015): Polybrominated diphenyl ethers (PBDEs) in eggshells of the Southern Ground-Hornbill (Bucorvus leadbeateri) and Wattled Crane (Bugeranus carunculatus) in South Africa. Chemosphere 118, 284-292

Daso AP, Akortia E, Okonkwo JO (2016): Concentration profiles, source apportionment and risk assessment of polycyclic aromatic hydrocarbons (PAHs) in dumpsite soils from Agbogbloshie e-waste dismantling site, Accra, Ghana. Environ Sci Pollut Res 23, 10883-10894

de Wit CA (2002): An overview of brominated flame retardants in the environment. Chemosphere 46, 583-624

EHC-172 1995: Tetrabromobisphenol A and derivatives, International Program on Chemical Safety, World Health Organization, Geneva, Switzerland.

Gallen C, Drage D, Kaserzon S, Baduel C, Gallen M, Banks A, Broomhall S, Mueller J (2016): Occurrence and distribution of brominated flame retardants and perfluoroalkyl substances in Australian landfill leachate and biosolids. Journal of hazardous materials 312, 55-64

Gorga M, Martínez E, Ginebreda A, Eljarrat E, Barceló D (2013): Determination of PBDEs, HBB, PBEB, DBDPE, $\mathrm{HBCD}, \mathrm{TBBPA}$ and related compounds in sewage sludge from Catalonia (Spain). Science of The Total Environment 444, 51-59

Gorgy T, Li LY, Grace JR, Ikonomou MG (2010): Polybrominated diphenyl ether leachability from biosolids and their partitioning characteristics in the leachate. Water, Air, \& Soil Pollution 209, 109-121

Huang K, Guo J, Lin K-f, Zhou X-y, Wang J-x, Zhou P, Xu F, Zhang M-L (2013): Distribution and temporal trend of polybrominated diphenyl ethers in one Shanghai municipal landfill, China. Environ Sci Pollut Res 20, 5299-5308

Kiddee P, Naidu R, Wong MH, Hearn L, Muller JF (2014): Field investigation of the quality of fresh and aged leachates from selected landfills receiving e-waste in an arid climate. Waste Management 34, 22922304 
Kim Y-J, Osako M, Sakai S-i (2006): Leaching characteristics of polybrominated diphenyl ethers (PBDEs) from flame-retardant plastics. Chemosphere 65, 506-513

Kong D, MacLeod M, Hung H, Cousins IT (2014): Statistical Analysis of Long-Term Monitoring Data for Persistent Organic Pollutants in the Atmosphere at 20 Monitoring Stations Broadly Indicates Declining Concentrations. Environmental Science \& Technology 48, 12492-12499

Kuramochi H, Kawamoto K, Miyazaki K, Nagahama K, Maeda K, Li XW, Shibata E, Nakamura T, Sakai SI (2008): Determination of physicochemical properties of tetrabromobisphenol A. Environmental Toxicology and Chemistry 27, 2413-2418

Kwan C, Takada H, Mizukawa K, Torii M, Koike T, Yamashita R, Rinawati, Saha M, Santiago E (2013): PBDEs in leachates from municipal solid waste dumping sites in tropical Asian countries: phase distribution and debromination. Environ Sci Pollut Res 20, 4188-4204

Letcher RJ, Lu Z, Chu S, Haffner GD, Drouillard K, Marvin CH, Ciborowski JJ (2015): Hexabromocyclododecane Flame Retardant Isomers in Sediments from Detroit River and Lake Erie of the Laurentian Great Lakes of North America. Bull Environ Contam Toxicol, 1-6

Li B, Danon-Schaffer MN, Li LY, Ikonomou MG, Grace JR (2012): Occurrence of PFCs and PBDEs in landfill leachates from across Canada. Water, Air, \& Soil Pollution 223, 3365-3372

Li Y, Li J, Deng C (2014): Occurrence, characteristics and leakage of polybrominated diphenyl ethers in leachate from municipal solid waste landfills in China. Environmental Pollution 184, 94-100

Mårtensson L, Bergström S, Svensson B-M, Mathiasson L (2007): Development and application of an analytical protocol for evaluation of treatment processes for landfill leachates. II. Evaluation of leachate treatment efficiency of different steps in a constructed pilot plant. International Journal of Environmental and Analytical Chemistry 87, 17-27

Morris S, Allchin CR, Zegers BN, Haftka JJ, Boon JP, Belpaire C, Leonards PE, Van Leeuwen SP, de Boer J (2004): Distribution and fate of HBCD and TBBPA brominated flame retardants in North Sea estuaries and aquatic food webs. Environmental science \& technology 38, 5497-5504

Muenhor D, Harrad S, Ali N, Covaci A (2010): Brominated flame retardants (BFRs) in air and dust from electronic waste storage facilities in Thailand. Environment International 36, 690-698

Nnorom IC, Osibanjo O (2008): Electronic waste (e-waste): Material flows and management practices in Nigeria. Waste Management 28, 1472-1479

Odusanya DO, Okonkwo JO, Botha B (2009): Polybrominated diphenyl ethers (PBDEs) in leachates from selected landfill sites in South Africa. Waste Management 29, 96-102

Olukunle OI, Sibiya IV, Okonkwo OJ, Odusanya AO (2015): Influence of physicochemical and chemical parameters on polybrominated diphenyl ethers in selected landfill leachates, sediments and river sediments from Gauteng, South Africa. Environ Sci Pollut Res Int 22, 2145-54

Osako M, Kim Y-J, Sakai S-i (2004): Leaching of brominated flame retardants in leachate from landfills in Japan. Chemosphere 57, 1571-1579

Puckett J, Westervelt S, Gutierrez R, Takamiya Y (2005): The digital dump: exporting re-use and abuse to Africa. Basel Action Network, Geneva, Switzerland.

Ryan JJ, Rawn DF (2014): The brominated flame retardants, PBDEs and HBCD, in Canadian human milk samples collected from 1992 to 2005; concentrations and trends. Environment international 70, 1-8

Tang L, Shao H-Y, Zhu J-Y, Xu G, Han T, Peng B-Q, Wu M-H (2015): Hexabromocyclododecane diastereoisomers in surface sediments from river drainage basins of Shanghai, China: occurrence, distribution, and mass inventory. Environ Sci Pollut Res, 1-8

UNEP 2009: Report of the Conference of Parties of the Stockholm Convention on Persistent Organic Pollutants on the work of its fourth meeting., United Nations Environment Programme Geneva, Switzerland.

WHO/IPCS 1994: Environmental Health Criteria 162. Brominated diphenyl ethers., International Programme on Chemical Safety, World Health Organization., Geneva, Switzerland.

WHO/IPCS 1997: Environmental Health Criteria 192. Flame retardants: a general introduction., International Programme on Chemical Safety, World Health Organization., Geneva, Switzerland.

Xiang N, Chen L, Meng X-Z, Dai X (2015): Occurrence of hexabromocyclododecane (HBCD) in sewage sludge from Shanghai: Implications for source and environmental burden. Chemosphere 118, 207-212

Zeng L, Yang R, Zhang Q, Zhang H, Xiao K, Zhang H, Wang Y, Lam PKS, Jiang G (2014): Current Levels and Composition Profiles of Emerging Halogenated Flame Retardants and Dehalogenated Products in Sewage Sludge from Municipal Wastewater Treatment Plants in China. Environmental Science \& Technology 48, 12586-12594 
Supplementary Table S1: Details of the target and reference ions employed during SIM analysis of PBDEs

\begin{tabular}{|c|c|c|c|}
\hline PBDE congeners & Retention time (min.) & Target ion & Reference ions \\
\hline PCNB (IS) & 3.375 & 242 & 220,255 \\
\hline BDE 17 & 4.625 & 246 & 248,408 \\
\hline BDE 28 & 4.740 & 246 & 248,406 \\
\hline BDE 47 & 5.460 & 326 & 324,486 \\
\hline BDE 77L & 5.765 & 498 & 496,500 \\
\hline BDE 100 & 6.030 & 404 & 406,566 \\
\hline BDE 99 & 6.250 & 404 & 406,566 \\
\hline BDE 154 & 6.860 & 484 & 486,482 \\
\hline BDE 153 & 7.260 & 484 & 486,482 \\
\hline BDE 139L & 7.380 & 496 & 494,498 \\
\hline BDE 183 & 8.490 & 721 & 562,564 \\
\hline BDE 209 & 15.020 & 799 & 238,400 \\
\hline BDE 209L & 15.045 & 811 & 971 \\
\hline
\end{tabular}

PBDE congeners in bold - surrogate standards; PCNB - Pentachloronitrobenzene; IS - internal standard. 
Supplementary Table 2: Optimised GC-EI-MS conditions employed for PBDEs analysis

\begin{tabular}{|c|c|}
\hline Parameters & Optimum conditions \\
\hline \multicolumn{2}{|l|}{ GC parameters } \\
\hline Injection volume & $1 \mu \mathrm{L}$ \\
\hline Carrier gas (\% purity) & Helium (99.999\%) \\
\hline Injection mode & Splitless \\
\hline Flow control mode & Linear velocity \\
\hline Injector temperature & $270^{\circ} \mathrm{C}$ \\
\hline Linear velocity & $80.0 \mathrm{~cm} / \mathrm{sec}$ \\
\hline Column flow & $2.33 \mathrm{ml} / \mathrm{min}$. \\
\hline Purge flow & $1.0 \mathrm{ml} / \mathrm{min}$ \\
\hline Equilibrium time & $3.0 \mathrm{~min}$. \\
\hline Sampling time & $1.00 \mathrm{~min}$. \\
\hline \multirow[t]{3}{*}{ Oven temperature programming } & $90^{\circ} \mathrm{C}$ held for $1.0 \mathrm{~min} .$, ramped $@ 40^{\circ} \mathrm{C} / \mathrm{min}$. to $200^{\circ} \mathrm{C}$, \\
\hline & ramped @2 $25^{\circ} \mathrm{C} / \mathrm{min}$ to $250^{\circ} \mathrm{C}$, ramped @ $7.5^{\circ} \mathrm{C} / \mathrm{min}$ to \\
\hline & $310^{\circ} \mathrm{C}$ held for $5 \mathrm{~min}$. \\
\hline \multicolumn{2}{|l|}{ MS parameters } \\
\hline Ion source temperature & $250^{\circ} \mathrm{C}$ \\
\hline Interface temperature & $280^{\circ} \mathrm{C}$ \\
\hline Solvent cut time & $2.0 \mathrm{~min}$. \\
\hline Acquisition mode & SIM \\
\hline Ionisation method & $\mathrm{EI}$ \\
\hline MS library scan range & $200-1000 \mathrm{amu}$ \\
\hline
\end{tabular}

